Dear author,

Please note that changes made in the online proofing system will be added to the article before publication but are not reflected in this PDF.

We also ask that this file not be used for submitting corrections. 
Perspective

\section{Interaction of silver nanoparticles with}

\section{mediterranean agricultural soils: Lab-controlled adsorption and desorption studies}

\section{Laura Torrent ${ }^{1}$, Eva Margui ${ }^{1}$, Ignasi Queralt ${ }^{2}$, Manuela Hidalgo $^{1}$, Mònica Iglesias ${ }^{1, *}$}

1. Department of Chemistry, University of Girona, C/M. Aurèlia Capmany, 69, 17003 Girona, Spain

2. Institute of Environmental Assessment and Water Research (IDAEA-CSIC), C. Jordi Girona, 18-26, 08034 Barcelona, Spain

\section{A R T I C L E I N F O}

Article history:

Received 14 September 2018

Revised 19 March 2019

Accepted 20 March 2019

Available online $\mathrm{xxxx}$

Keywords:

Silver nanoparticles

Agricultural soils

Sorption kinetics

Leaching tests

Single-particle inductively coupled

plasma mass spectrometry

\section{Introduction}

During recent years, the use of manufactured nanoparticles (MNPs) for domestic and industrial purposes has grown tremendously (Pulit-Prociak and Banach, 2016; Sajid et al., 2015). The fraction of atoms at the nanoparticle surface is high

\begin{abstract}
A B S T R A C T
The production of silver nanoparticles (AgNPs) has increased tremendously during recent years due to their antibacterial and physicochemical properties. As a consequence, these particles are released inevitably into the environment, with soil being the main sink of disposal. Soil interactions have an effect on AgNP mobility, transport and bioavailability. To understand AgNP adsorption processes, lab-controlled kinetic studies were performed. Batch tests performed with five different Mediterranean agricultural soils showed that cation exchange capacity and electrical conductivity are the main parameters controlling the adsorption processes. The adsorption kinetics of different sized (40, 75, 100 and $200 \mathrm{~nm})$ and coated (citrate, polyvinylpyrrolidone and polyethyleneglycol (PEG)) AgNPs indicated that these nanoparticle properties have also an effect on the adsorption processes. To assess the mobility and bioavailability of AgNPs and to determine if their form is maintained during adsorption/desorption processes, loaded soils were submitted to leaching tests three weeks after batch adsorption studies. The DIN 38414-S4 extraction method indicated that AgNPs were strongly retained on soils, and single-particle inductively coupled plasma mass spectrometry confirmed that silver particles maintained their nanoform, except for $100 \mathrm{~nm}$ PEG-AgNPs and $40 \mathrm{~nm}$ citrate-coated AgNPs. The DTPA (diethylenetriaminepentaacetic acid) leaching test was more effective in extracting silver, but there was no presence of AgNPs in almost all of these leachates.

(c) 2019 The Research Center for Eco-Environmental Sciences, Chinese Academy of Sciences.
\end{abstract} Published by Elsevier B.V.

because of its nanosize (1-100 $\mathrm{nm})$, thus promoting both the 55 specific surface area and adsorption capacity. Consequently, 56 the physicochemical characteristics (electrical conductivity, 57 mechanical strength, optical or magnetic properties) of nano- 58 particles are unique, and differ from those of their bulk 59 counterparts. Among different types of nanoparticles, metallic 60

\footnotetext{
*Corresponding author. E-mails: laura.torrent@udg.edu, (Laura Torrent), monica.iglesias@udg.edu. (Mònica Iglesias).
} 
MNPs have experienced substantial growth in the industry, with silver nanoparticles (AgNPs) one of the most produced NPs due to their effective biocidal activity. Their applications are spread across a variety of commercial goods such as foods, textiles, construction, medicines, cosmetics, power, pharmacy, biomedicine, household goods and agriculture (Pulit-Prociak and Banach, 2016; Pachapur et al., 2016; Van Koetsem et al., 2015). As a consequence of the widespread production of AgNPs, these particles are inevitably released through different pathways into the environment (air, water and soil). Soil is the biggest sink of disposal for most of the released MNPs. The main source of entry of these emerging contaminants to soils is through the application of sewage sludge from wastewater treatment plants (WWTPs) to agricultural lands. In WWTPs, AgNPs can undergo different transformations (e.g., dissolution, oxidation or sulfidation), with transformation to silver sulfide in sewage sludge being the main pathway. However, anthropogenic silver nanoparticles can also enter agricultural land directly via unintentional emissions, accidental spills or application of nanopesticides (Li et al., 2017; Pachapur et al., 2016; Azimzada et al., 2017). Soil matrices are relatively complex because they present a solid phase, consisting of organic matter and minerals, and an aqueous phase that contains various amounts of natural colloidal/particulate materials (Peralta-Videa et al., 2011; Tourinho et al., 2012). Consequently, AgNP interactions with soils are difficult to interpret. These interactions lead to processes, such as aggregation/agglomeration, dissolution to metal ions or sorption onto surfaces, which are responsible for their mobility, transport and bioavailability in the environment (Tourinho et al., 2012). Aggregation and agglomeration are associations of particles due to physicochemical processes including Van der Waals forces, electrostatic interactions or Brownian motion. Dissolution of AgNPs into their constituent atoms is governed by diverse phenomena, such as chemical reactions that take place due to the presence of oxygen, chlorine and enzymes (Pachapur et al., 2016). Deposition occurs when particles are retained on a solid surface or when aggregation (both homo- and hetero-aggregation)/agglomeration takes place. Adsorption of nanoparticles onto the solid components of soils is influenced by particle properties (size, shape, surface charge, surface and core chemistry, capping agent, agglomeration state, crystallinity, redox potential, catalytic activity and porosity) as well as soil features ( $\mathrm{pH}$, organic matter content, ionic strength, zeta potential and texture) (Darlington et al., 2009; Van Koetsem et al., 2015). The capping agent is one of the main determinant characteristics since it affects the surface charge, which governs attraction/repulsion interactions among particles, and the steric hindrance (Christian et al., 2008; Schultz et al., 2015; Tourinho et al., 2012; McGillicuddy et al., 2017; Lin et al., 2012). Additionally, particle size is another property that strongly influences immobilization on soil surfaces, especially when there is aggregate formation (Darlington et al., 2009; Hoppe et al., 2014; He et al., 2019).

Batch experiments are commonly used in order to understand the retention and transport of contaminants in soils. This approach allows one to examine the retention under well-defined conditions in an easier and faster way compared to column experiments (Treumann et al., 2014; Plassard et al., 2000). However, as stated in different reports, nanoparticle dispersions are thermodynamically unstable and their behavior cannot be described as an equilibrium process. 121 Despite this fact, batch tests can still provide valuable 122 information on nanoparticle attachment/detachment kinetics 123 (Praetorius et al., 2014; Cornelis, 2015). For example, Cornelis 124 et al. (2012) concluded from batch tests that adsorption of 125 polyvinylpyrrolidone (PVP) coated AgNPs (negatively charged) 126 on iron and aluminum oxides and mineral clay edges may be 127 important in retention processes in soils. An additional batch 128 retention experiment using sterically stabilized AgNPs deter- 129 mined that immobilization of nanosilver depends on soil 130 properties such as clay content, $\mathrm{pH}$ and calcium content 131 (Hoppe et al., 2014). Furthermore, organic matter content is 132 also relevant in adsorption of AgNPs onto silt particles, as 133 stated by Klitzke et al. (2015).

Scarce information on the desorption of AgNPs from soil 135 particles to the liquid phase exists in the published literature 136 (Coutris et al., 2012; Navarro et al., 2014). To evaluate the 137 potential mobility and bioavailability of metals in polluted 138 soils, leaching tests are frequently used (Hoppe et al., 2015), 139 which gives information related to soil-plant transfer of 140 pollutants and their migration in a soil profile that is 141 connected with groundwater (Rauret, 1998). More recently, 142 some leaching tests have been used to evaluate the bioacces- 143 sibility of AgNPs from soils in the human gastrointestinal tract 144 (Dang et al., 2018).

Common analytical tools for quantitative determination of 146 AgNPs in liquid extracts are inductively coupled plasma 147 optical emission spectrometry (ICP-OES) and inductively 148 coupled plasma mass spectrometry (ICP-MS). These analytical 149 techniques allow the determination of total metal content, 150 hindering the ability to distinguish the metallic AgNPs from 151 other silver (Ag) species present in the solution (Koopmans et 152 al., 2015). However, in recent years the use of single-particle 153 ICP-MS (SP-ICP-MS) to detect and characterize MNPs at trace 154 levels in environmental samples has increased (Mitrano et al., 155 2014; Montaño et al., 2014). Analysis with SP-ICP-MS requires 156 nanoparticle suspensions that have been sufficiently diluted 157 and a short dwell time to ensure that a maximum of one 158 particle is measured in each integration time. Once injected 159 into the plasma, the discrete particle is vaporized, atomized 160 and ionized, producing a burst of ions that can be measured as 161 a single pulse (Laborda et al., 2013; Tuoriniemi et al., 2012; 162 Yang et al., 2014). This analytical technique allows differen- 163 tiation between nanosilver and soluble silver species and also 164 can give information about the size distribution (Majedi and 165 Lee, 2016).

In this work, batch experiments and leaching tests were 167 carried out in order to understand the adsorption and 168 desorption processes of AgNPs with soils. The goal of this 169 study was to determine the adsorption kinetics of AgNPs with 170 different soils, using different particle sizes and coatings, and 171 assessing the desorption of these particles by leaching tests. 172 Furthermore, the possible AgNP transformations during the 173 studied interaction processes were evaluated by analyzing the 174 samples by the SP-ICP-MS technique. To our knowledge, few 175 research papers exist involving the adsorption and desorption 176 of AgNPs from soils that test nanoparticles with different 177 physicochemical properties. In addition, none of them employ 178 SP-ICP-MS for AgNP detection after the adsorption and 179 desorption processes. 


\section{Materials and methods}

\subsection{Chemicals, materials, apparatus and instrumentation}

ICP-OES standard solutions were prepared from a silver stock solution (silver nitrate $\left(\mathrm{AgNO}_{3}\right)$ in nitric acid $\left.\left(\mathrm{HNO}_{3}\right)\right)$ of $(1000 \pm$ 2) $\mathrm{mg} / \mathrm{L}$ from Merck (Germany). High purity water from a Milli- $Q$ purification system (Millipore Corp., Bedford, MA) was employed for the leaching experiments (DIN 38414-S4 extraction method). It was also used to dilute stock solutions and soil leachates (supernatants). Triethanolamine (TEA) (Sigma-Aldrich, Germany), diethylenetriaminepentaacetic acid (DTPA) (Panreac, Spain) and calcium chloride dehydrate $\left(\mathrm{CaCl}_{2} \cdot 2 \mathrm{H}_{2} \mathrm{O}\right.$, Panreac, Spain) were utilized to prepare the extracting solution for the DTPA leaching test.

Batch adsorption experiments and leaching tests were performed employing LD-76 rotary mixers (Dinko, Spain). In order to break down the possible agglomerates of AgNPs, an ultrasonic bath (J.P. Selecta, Spain) was used. A Rotofix 32A centrifuge (Hettich-Zentrifugen, Germany) was utilized to separate the soil and the soil extract after kinetic adsorption tests and leaching tests.

Total silver content in aqueous suspensions from adsorption and leaching experiments was determined using an ICPOES Vertical Dual View 5100 system (Agilent Technologies, Japan), with calibration curves ranging between 5 and $350 \mu \mathrm{g} / \mathrm{kg}$ silver concentration. SP-ICP-MS for silver nanoparticle detection in aqueous leachates was perfomed using a quadrupolebased ICP-MS Agilent 7500c system (Agilent Technologies, Japan) equipped with Octapole Reaction System (ORS) technology. The instrumental characteristics and measurement conditions of the two intruments are summarized in Appendix A Table S1. Histograms of the results were calculated and plotted using Microsoft Excel software.

\subsection{Nanoparticles}

Silver nanoparticles of different sizes and coatings were tested in this work. Two suspensions of silver nanoparticles stabilized with sodium citrate (citrate-AgNPs) of 40 and $100 \mathrm{~nm}$ were obtained from Sigma-Aldrich (USA) and one of $200 \mathrm{~nm}$ from NanoComposix (USA). Polyvinylpyrrolidone-coated silver nanoparticles (PVP-AgNPs) of 75 and $100 \mathrm{~nm}$ and polyethyleneglycol-coated silver nanoparticles (PEG-AgNPs) of $100 \mathrm{~nm}$ were purchased from NanoComposix (USA). The principal difference between these nanoparticles was the zeta potential, which depends on the capping agent and is related to the surface charge. The most negative zeta potential at $\mathrm{pH} 7$ was found for citrate-AgNPs and the least negative for PEGAgNPs, which was almost neutral (Nanocomposix. Standard Capping Agents, 2018). Detailed information about the characteristics of the studied AgNPs can be found on the manufacturers' webpages.

\subsection{Soils studied}

Five Mediterranean agricultural soils with different physicochemical properties were tested in order to evaluate their influence in AgNP adsorption processes. The five studied soils were sampled at different locations from Barcelona and 235 Girona provinces (NE Spain): Soil 1 and Soil 2 (Vallcebre), Soil 236 3 (Castellbisbal), Soil 4 (Gavà) and Soil 5 (La Tallada 237 d'Empordà). These soils were selected to cover the variety of 238 soils along this Mediterranean region. Composite and repre- 239 sentative surface soil samples were obtained by combining 240 several subsamples per location. They were collected using a 241 polypropylene shovel and subsequently transferred to clean 242 polypropylene bags. In the laboratory, soil samples were dried 243 at room temperature, sieved $(2 \mathrm{~mm})$ and stored in polypro- 244 pylene containers.

The particle size distribution (Appendix A Table S2) 246 revealed strong differences regarding the smallest sizes, 247 $<0.125 \mathrm{~mm}$, ranging from near $4 \%$ for Soil 3 to around $50 \% 248$ for Soil 4. Soil mineralogy was determined by X-ray diffraction 249 (XRD), following randomly oriented powder methodology for 250 bulk composition and the oriented aggregate method for the 251 identification of clay minerals. From the results, (Appendix A 252 Table S3) studied soils could be classified as marly soils, 253 characterized by the prevalence of carbonates (mainly calcite, 254 $\mathrm{CaCO}_{3}$ ) and quartz. Soils from the Vallcebre area (Soil 1 and 255 Soil 2) differed in the type of carbonate, dolomite $\left(\mathrm{MgCaCO}_{3}\right) 256$ for Soil 1 and a noticeable content of gypsum for Soil 2. 257 Dealing with the content of clay minerals, Soils 1 and 2 were 258 characterized by the presence of swelling clays of the smectite 259 group, with a minor amount of kaolinite, whereas the rest of 260 the soils exhibited different clay assemblages, illite-kaolinite 261 for Soil 3 and chlorite-illite for Soils 4 and 5. Clay mineralogy is 262 the key factor in the cation exchange capacity (CEC) of soils. 263 Pure smectite has a CEC from 80 to $150 \mathrm{mEq} / 100 \mathrm{~g}$, with illite 264 and chlorite ranging from 10 to $40 \mathrm{mEq} / 100 \mathrm{~g}$ and kaolinite 265 from 3 to $15 \mathrm{mEq} / 100 \mathrm{~g}$. Minor quantities of feldspars and 266 hematite were also detected in the XRD runs.

The physicochemical properties of these studied soils are 268 shown in Table 1. As can be expected from the mineralogy, 269 the $\mathrm{pH}$ of the soil samples was neutral to slightly basic. The 270 cation exchange capacity, around three times higher in Soils 1271 and 2, was directly related to the presence of smectite. The 272 electrical conductivity was very high in Soil 2 due to the 273 presence of gypsum, exhibiting a wide variety for the rest of 274 the soils, and the organic matter was nearly constant (5\%-6\%), 275 except for Soil 5 that had the lowest content.

276

\subsection{Adsorption studies}

277

Batch adsorption experiments were performed in order to 278 investigate the interaction between AgNPs and soil in lab- 279

Table 1 - Physicochemical characteristics of studied soils.

\begin{tabular}{|c|c|c|c|c|c|}
\hline & $\begin{array}{c}\mathrm{pH} \\
\text { (in } \mathrm{H}_{2} \mathrm{O} \text { ) }\end{array}$ & $\begin{array}{c}\text { Moisture } \\
(\%)\end{array}$ & $\begin{array}{l}\text { O.M. } \\
(\%)\end{array}$ & $\begin{array}{c}\text { CEC } \\
(\mathrm{meq} / 100 \mathrm{~g})\end{array}$ & $\begin{array}{c}\mathrm{EC} \\
(\mu \mathrm{S} / \mathrm{cm})\end{array}$ \\
\hline Soil 1 & 8.0 & 13.3 & 6.5 & 20.1 & 105.1 \\
\hline Soil 2 & 7.4 & 13.05 & 5 & 18.9 & 2460 \\
\hline Soil 3 & 7.6 & 9.3 & 5.7 & 6.5 & 276.5 \\
\hline Soil 4 & 7.4 & 3.7 & 6.1 & 7 & 427.3 \\
\hline Soil 5 & 7.1 & 0.5 & 1.8 & 5.3 & 87.3 \\
\hline
\end{tabular}

O.M.: organic matter content. CEC: cation exchange capacity. EC: $\quad$ t1.10 electrical conductivity. 
controlled conditions. For this purpose, $0.5 \mathrm{~g}$ of soil was weighed into polystyrene tubes. Then, $20 \mathrm{~mL}$ of a 1 or $10 \mathrm{mg} /$ $\mathrm{L}$ aqueous suspension of AgNPs was added followed by agitation with a rotary mixer at $35 \mathrm{r} / \mathrm{min}$.

Afterwards, samples were removed in duplicate at specific times (10 min, $20 \mathrm{~min}, 30 \mathrm{~min}, 1 \mathrm{hr}, 2 \mathrm{hr}, 4 \mathrm{hr}$ or $6 \mathrm{hr}$ ) and centrifuged at $3500 \mathrm{r} / \mathrm{min}$ for $8 \mathrm{~min}$. Finally, the supernatant was transferred to a new polystyrene tube and stored overnight at $4^{\circ} \mathrm{C}$ until analysis.

Prior to analysis by ICP-OES, liquid samples were ultrasonicated for $5 \mathrm{~min}$ to break down the possible agglomerates of silver nanoparticles present in the aqueous suspension. Then, samples were shaken vigorously for $1 \mathrm{~min}$ and filtered through a $0.45 \mu \mathrm{m}$ cellulose acetate filter (Whatman, Filterlab, Spain) to remove suspended soil particles. Finally, the samples were analyzed by ICP-OES and the total silver content was quantified using an ionic silver $\left(\mathrm{Ag}^{+}\right)$calibration curve. All experiments were carried out in duplicate.

\subsection{Leaching studies: DIN 38414-S4 and DTPA extraction}

In order to study the possible release of AgNPs from soils, two leaching tests named DIN 38414-S4 (German Standard legislation, 1984) and DTPA (Quevauviller, 1998) were performed. These leaching tests were selected to allow the evaluation of the mobility and bioavailability of metals in the environment. The DIN 38414-S4 leaching test gives information about the more mobilized metals and the DTPA leaching method predicts the bioavailability of metals to plants (Rauret, 1998; Kosson et al., 1996). To this aim, soils containing known amounts of adsorbed AgNPs were tested 21 days after the adsorption experiment.

For the DIN 38414-S4 extraction procedure, $5 \mathrm{~mL}$ of Milli-Q water was added to $0.5 \mathrm{~g}$ of loaded soil and the mixture was submitted to rotation with a rotary mixer $(35 \mathrm{r} / \mathrm{min})$ for $24 \mathrm{hr}$ at room temperature $\left(22^{\circ} \mathrm{C}\right)$. In the case of the DTPA extraction test, $5 \mathrm{~mL}$ of DTPA solution $(0.005 \mathrm{~mol} / \mathrm{L}$ DTPA, $0.01 \mathrm{~mol} / \mathrm{L}$ TEA, $0.5 \mathrm{~mol} / \mathrm{L} \mathrm{CaCl}{ }_{2} \cdot 2 \mathrm{H}_{2} \mathrm{O}$ adjusted to $\mathrm{pH} 7.3$ ) was agitated ( $35 \mathrm{r} / \mathrm{min}$ ) with $0.5 \mathrm{~g}$ of loaded soil for $2 \mathrm{hr}$ at room temperature $\left(22^{\circ} \mathrm{C}\right)$.

After these contact times, samples were centrifuged for $8 \mathrm{~min}$ at $3500 \mathrm{r} / \mathrm{min}$, after which the supernatants were transferred to new polystyrene tubes and stored overnight at $4^{\circ} \mathrm{C}$ until analysis by ICP-OES and SP-ICP-MS techniques.

\subsection{Evaluation of the presence of Ag as AgNPs by SP-ICP-MS analysis}

SP-ICP-MS was used to confirm the presence of AgNPs in the stripping solutions. To obtain good results in SP-ICP-MS, the Ag concentration in the form of AgNPs should be very low to afford a solution that has at maximum one particle in the volume aspirated during the dwell time $(10 \mathrm{msec})$. For this reason, the Ag concentration of the samples was determined by the ICP-OES technique before SP-ICP-MS analysis to determine which dilution was needed to obtain a final solution of approximately $0.8 \mu \mathrm{g} / \mathrm{L}$. Previous to the ICP-OES analysis, in order to remove the suspended soil particles, samples were filtered through a cellulose acetate filter of $0.45 \mu \mathrm{m}$ after being ultrasonicated for $5 \mathrm{~min}$ and shaken for $1 \mathrm{~min}$ to avoid the possibility of agglomerates. Finally, the samples were analyzed by SP-ICP-MS to determine if silver 336 was present in the leachate solution (supernatant) in 337 nanosilver form. In the case of DTPA solutions, the stability 338 of AgNPs had been previously verified. The presence of 339 nanoparticles was confirmed in this media for $100 \mathrm{~nm} 340$ AgNPs with the three different coatings after $2 \mathrm{hr}$ of agitation. 341

\section{Results and discussion}

\subsection{Stability and storage of AgNP solutions}

Some recent publications have highlighted the potential 345 alteration of the dispersion state of nanoparticles by labora- 346 tory procedures (Simonet and Valcárcel, 2009). For this reason, 347 previous to the soil adsorption studies, some experiments 348 were carried out in order to evaluate the stability of silver 349 nanoparticle suspensions submitted to different treatments 350 and storage conditions. Specifically, various times of storage 351 ( $<6 \mathrm{hr}$ and 6 days) at different temperatures (around $4^{\circ} \mathrm{C}$ and 352 around $-20^{\circ} \mathrm{C}$ ) were evaluated. Moreover, the effect of 353 filtration of these suspensions was also tested. Results can 354 be observed in Appendix A Fig. S1.

355

Good recoveries of fresh suspensions (95\%-100\%) assessed 356 using an ICP-OES system and silver standard solutions for 357 quantification purposes confirmed the good performance of 358 the analytical procedure.

359

It can be seen that the storage of aqueous silver nanopar- 360 ticles suspensions during 6 days caused a $40 \%$ decrease in 361 their recovery with respect to the ones stored for $<6 \mathrm{hr}$ for all 362 types of AgNPs tested (significant statistical differences by 363 Student's t-test, $\left.t_{\text {critical }}<t_{\text {experimental }}\right)$. Nevertheless, a recovery 364 of $(104.6 \% \pm 1.2 \%)$ was obtained from an aqueous suspension 365 of citrate-coated silver nanoparticles $(100 \mathrm{~nm})$ after being 366 stored $24 \mathrm{hr}$ at $4^{\circ} \mathrm{C}$ (data not shown in the bar chart). No 367 significant statistical differences were observed (Student's t- 368 test, $t_{\text {critical }}>t_{\text {experimental }}$ ) between storing the samples at 4 or 369 at $-20^{\circ} \mathrm{C}$. Finally, it was shown that the filtration of fresh 370 samples does not cause any effect on the recovery of AgNPs 371 (no significant statistical differences by Student's t-test, 372 $\left.t_{\text {critical }}>t_{\text {experimental }}\right)$. Moreover, the supernatant solution had 373 no effect on silver recovery $(94.6 \% \pm 1.3 \%)$ of $100 \mathrm{~nm}$ PVP- 374 AgNPs after filtration. However, the filtration process caused 375 an important decrease in the AgNP concentration when silver 376 nanoparticles aqueous suspensions had been stored at $-20^{\circ} \mathrm{C} 377$ (significant statistical differences by Student's t-test, t- 378 critical $<t_{\text {experimental }}$. Some aggregation processes have been 379 reported for nanoparticles suspension under these low 380 temperatures (Sigfridsson et al., 2013). These aggregations 381 can produce a loss of particles when they are subjected to 382 filtration afterwards. Taking into account all these results, the 383 adsorption studies could be carried out analyzing the samples 384 after storage for a maximum of $24 \mathrm{hr}$ at $4^{\circ} \mathrm{C}$ and subjecting the 385 samples to a filtration process if necessary.

386

\subsection{Adsorption of AgNPs in agricultural soils: Kinetic studies 387}

Some preliminary experiments were performed in order to 388 determine the appropriate amount of soil and the volume and 389 concentration of silver nanoparticle suspensions. The aim of 390 
these experiments was to establish the conditions that permitted the evaluation of the adsorption of AgNPs onto soil surfaces. For this purpose, 2, 1 and $0.5 \mathrm{~g}$ of soil were put in contact with $20 \mathrm{~mL}$ of a $1 \mathrm{mg} / \mathrm{L}$ citrate-AgNPs $(100 \mathrm{~nm})$ suspension (Appendix A Fig. S2). Likewise, 10, 15 and $20 \mathrm{~mL}$ of $75 \mathrm{~nm}$ PVP-AgNP suspensions (1, 5 and $10 \mathrm{mg} / \mathrm{L}$ concentrations) were mixed with $0.5 \mathrm{~g}$ of soil (Appendix A Fig. S3). In both cases the soil and nanoparticle suspensions were stirred under rotary agitation conditions ( $35 \mathrm{r} / \mathrm{min}$ ) for $2 \mathrm{hr}$. Afterwards, the silver concentration in the supernatant was determined by ICP-OES analysis. Results showed that a smaller amount of soil $(0.5 \mathrm{~g})$ and greater volume of solution $(20 \mathrm{~mL})$ gave higher Ag concentrations in the supernatant suspensions, indicating slower kinetics in comparison with that obtained using high soil amounts. This is favorable for detection of the differences in adsorption kinetics of different types of AgNPs. Therefore, it was decided to use $0.5 \mathrm{~g}$ of soil and $20 \mathrm{~mL}$ of a $10 \mathrm{mg} / \mathrm{L}$ silver nanoparticle suspension (PVPAgNPs $75 \mathrm{~nm}$ ) only for testing the influence of soil properties on AgNP adsorption. For the other tests (coating and size effects), $0.5 \mathrm{~g}$ of soil and $20 \mathrm{~mL}$ of $1 \mathrm{mg} / \mathrm{L}$ AgNP suspensions were used due to the low concentration of the stock solutions available $(20 \mathrm{mg} / \mathrm{L})$. Using these conditions, a kinetic study was undertaken.

The study was conducted with all the soils described in Section 1.3 (for details of soil characteristics see Appendix A Tables S2 and S3). The results obtained using AgNPs of $75 \mathrm{~nm}$ coated with PVP are shown in Fig. 1a. As can be seen, the adsorption rates obtained for all tested soils after $4 \mathrm{hr}$ of rotation were high ( $80 \%$ of adsorption). Soil 2 showed the fastest adsorption rate, reaching almost $100 \%$ adsorption in less than $10 \mathrm{~min}$. The main characteristics of this soil are its high electrical conductivity and cation exchange capacity. This fact agrees with different works that point out the increase of AgNP adsorption on soils with increasing ionic strength (Anjum et al., 2013). Thus, both homo- and heteroaggregation processes could be responsible of this adsorption. On the other hand, Soil 3 after half an hour of the kinetic adsorption study presented the slowest adsorption rate (75\%). This soil had one of the lowest cation exchange capacity values; however, its electrical conductivity was higher than that of Soil 1, which shows a higher rate of adsorption. After $4 \mathrm{hr}$ of the kinetic study, the slowest adsorption rate was obtained for Soil 5, which had the lowest cation exchange capacity and electrical conductivity. The size distribution of soil particles seems not to have a great influence in the adsorption rate, although the soils with a lower adsorption rate (Soils 3, 4 and 5) were those with greater amounts of small soil particles. Cornelis et al. (2013) determined a correlation between clay content and AgNP retention by natural soils. This correlation seems to be explained by the hetereocoagulation of AgNPs with colloids naturally present in soils.

Using these results, an approximate value for the affinity coefficient, $\alpha$, could be calculated following the methodology developed by Barton et al. (2014). For removal of AgNP suspensions at time $t, r(t)$ was calculated as $r(t)=\left(C_{0}-C_{t}\right) / C_{0}$, with $C_{0}(\mu g / L)$ being the initial AgNP mass concentration and $C_{t}$ $(\mu \mathrm{g} / \mathrm{L})$ the AgNP mass concentration in the supernatant suspension at time $t$ (min). Afterwards, $\ln \left(r C_{0} / C_{t}+1\right)$ vs time was plotted
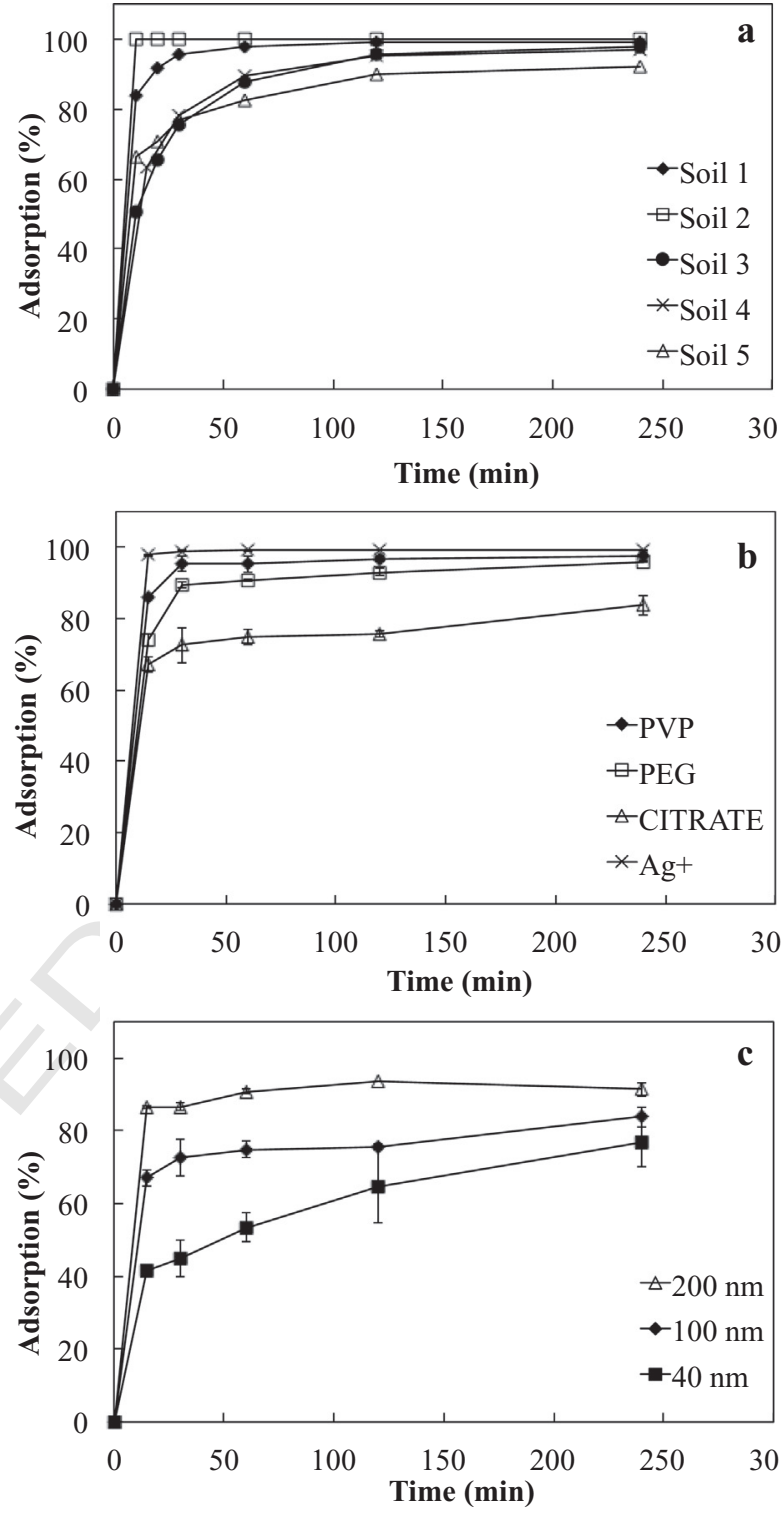

Fig. 1 - Percentage of adsorption of different silver nanoparticles in agricultural soils $(0.5 \mathrm{~g}$ of soil and $20 \mathrm{~mL}$ of nanoparticle suspension). (a) Comparison of agricultural soils with different physicochemical properties using a suspension of $10 \mathrm{mg} / \mathrm{L}$ of $75 \mathrm{~nm} \varnothing$ polyvinylpyrrolidone (PVP) coated AgNPs. (b) Comparison of different coatings (PVP, polyethyleneglycol (PEG), citrate) of $100 \mathrm{~nm} \emptyset$ nanoparticles using Soil 3 and a solution of $1 \mathrm{mg} / \mathrm{L}$ of total silver. (c) Comparison of different sizes of citrate silver nanoparticles using Soil 3 and a solution of $1 \mathrm{mg} / \mathrm{L}$ total silver concentration.

and a linear portion was obtained for these plots (between 10 and 451 $60 \mathrm{~min}$ ) except for Soil 2, which showed very fast adsorption 452 (Appendix A Fig. S4). The values of the slope of this linear portion 453 correspond to the product $\alpha \beta B$, which is a measure of the relative 454 affinity of the nanoparticles for soil. $\beta$ and B are the collision 455 frequency and the concentration of soil particles respectively, 456 which in this case were constant. From these calculations the 457 
values of $\alpha \beta B$ determined were $6.42 \times 10^{-4}, 4.88 \times 10^{-4}$, $3.21 \times 10^{-4}$ and $2.16 \times 10^{-4}$ for soils $1,3,4$ and 5 respectively. These affinity coefficients thus obtained are in agreement with the soil adsorption kinetics, because Soil 1 is one of the soils with the fastest AgNP adsorption kinetics and its affinity coefficient is the highest, meanwhile Soil 5 shows the slowest AgNP adsorption kinetics and its affinity coefficient is the lowest.

\subsection{Effect of the coating and size of AgNPs in soil adsorption}

Soil 3 was chosen to study the adsorption behavior of different types of nanoparticles (surface and size) because, as observed previously, this soil had an intermediate affinity toward AgNPs among all the studied soils.

First of all, the adsorption kinetics of different coated silver nanoparticles (PVP, PEG and citrate) onto Soil 3 was compared using AgNPs of $\varnothing 100 \mathrm{~nm}$. For comparison purposes, the adsorption kinetics of silver ions (added as $\mathrm{AgNO}_{3}$ ) was also examined. Results are depicted in Fig. $1 \mathrm{~b}$.

As can be observed, $\mathrm{Ag}^{+}$showed a faster adsorption rate than silver nanoparticles, reaching $100 \%$ of adsorption in $15 \mathrm{~min}$. In fact, different works underline the high capacity of $\mathrm{Ag}^{+}$to be adsorbed by soils, either by thiol groups or to colloidal particles (Anjum et al., 2013). The different types of AgNPs showed quite fast and similar adsorption rates, achieving a steady-state concentration in less than $60 \mathrm{~min}$. Nevertheless, AgNPs with a citrate surface coating were less adsorbed (80\%) than PEG- and PVP-coated nanoparticles, which reached almost $100 \%$ adsorption under the present conditions. For citrate particles an additional value was determined at $6 \mathrm{hr}$ (data not shown), which was very similar to the adsorption value obtained at $4 \mathrm{hr}$. The lower adsorption rate of citrate-AgNPs respect to PEG-AgNPs and PVP-AgNPs could be due to their zeta potential, which is controlled by the $\mathrm{pH}$ of the solution. Zeta potential, which is the charge at the surface of the electrical double layer, is a key indicator of the stability of colloidal dispersions. Usually, capping of the particles with highly negative zeta potential indicates the increase of particle stabilization. As detailed by the manufacturer, citrate-AgNPs present a highly negative zeta potential (negatively charged) in comparison to PVP-AgNPs and PEGAgNPs. Thus, citrate-AgNPs are more stable and their aggregation tendency is lower due to higher repulsion with negatively charged soil surfaces in comparison to other tested AgNPs (Tech Note: Zeta/pH Curves and Isoelectric Point Data for Standard Nanocomposix Silver Citrate and PVP Nanoparticle Dispersions, 2012; Prathna et al., 2011; Hoppe et al., 2015).

Adsorption rates of AgNPs with different sizes should also be compared. To this aim, citrate-coated AgNPs of 40, 100 and $200 \mathrm{~nm}$ diameters were used. From the results (Fig. 1c) it can be observed that silver nanoparticles with a size of $200 \mathrm{~nm}$ were adsorbed faster in comparison to $40 \mathrm{~nm}$ AgNPs. In addition, the largest AgNPs were almost totally adsorbed (90\%) in $1 \mathrm{hr}$ of contact time; meanwhile, the smallest AgNPs (40 nm) reached a value of $50 \%$, achieving a $75 \%$ after $4 \mathrm{hr}$. It must be taken into account that in this work, we compared suspensions with the same Ag mass concentration but different particle number concentrations. The smaller the nanoparticle size, the higher the particle number concentration for the same Ag mass concentration. So, there were more particles able to be adsorbed in the $40 \mathrm{~nm}$ AgNP solution than in $100 \mathrm{~nm}$ or in 516 $200 \mathrm{~nm}$ ones. These results agree with those obtained by He et 517 al. (2019) and seem to indicate that no dissolution process is 518 taking place for AgNPs. On one hand, smaller nanoparticles are 519 reported to dissolve more quickly. On the other hand, silver 520 ions are more quickly retained in soils. Both facts point in the 521 opposite direction as the behavior observed.

522

Finally, the adsorption rates of all types of nanoparticles 523 using the five soils considered in this study were compared. In 524 all cases the concentration of silver in the supernatant 525 solution was determined after two hours of rotation ( $35 \mathrm{r} / 526$ $\min$ ) at $22^{\circ} \mathrm{C}$. Higher concentrations of silver in the superna- 527 tant indicated lower adsorption degree on the soil. Results are 528 depicted in Fig. 2.

As can be seen in this figure, the lowest adsorption was 530 obtained for $100 \mathrm{~nm}$ citrate-coated nanoparticles in compar- 531 ison to $100 \mathrm{~nm}$ PVP-AgNPs and PEG-AgNPs, observing signif- 532 icant statistical differences, except for Soil 2 (Student's t-test, 533 $\left.t_{\text {critical }}<t_{\text {experimental }}\right)$. AgNPs with PVP and PEG surfaces 534 $(100 \mathrm{~nm})$ showed similar results and higher adsorption than 535 citrate-coated nanoparticles (no significant statistical differ- 536 ences by Student's t-test, $t_{\text {critical }}>t_{\text {experimental }}$ ), except for Soil 537 5, where significant statistical differences were observed 538 (Student's t-test, $t_{\text {critical }}<t_{\text {experimental }}$ ). This different behavior 539 of Soil 5 could be due to its lower organic matter content. 540 Hoppe et al. (2014) stated that citrate-stabilized AgNP adsorp- 541 tion processes in soils are related to the soil organic matter 542 content, which tends to be negatively charged and may 543 hamper access to positively charged groups (Ketterings et al., 544 2007). Thus, the low organic matter content of Soil 5, in 545 comparison to other studied soils, indicates that the particles 546 of this soil may contain less negative charges, favoring the 547 adsorption of citrate-AgNPs (highly negatively charged). 548

Significant statistical differences were also observed 549 between small citrate nanoparticles $(40 \mathrm{~nm})$ and the big 550 ones $(100 \mathrm{~nm})$ in all the tested soils (Student's t-test, $t_{\text {critical }}>551$ $t_{\text {experimental) }}$ except for Soil 1 (Student's $t$-test, $t_{\text {critical }}>552$

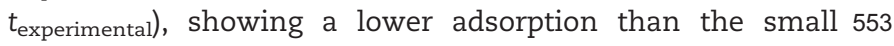
ones. As stated above, the reason for this phenomenon can 554 be the presence of more particles in the $40 \mathrm{~nm}$ AgNP solution 555 than in the $100 \mathrm{~nm}$ one.

When comparing the behaviors of the soils, again Soil 2557 showed a higher adsorption degree for all types of AgNPs in 558 comparison to the other studied soils in this work (significant 559 statistical differences by Student's $t$-test, $\left.t_{\text {critical }}>t_{\text {experimental }}\right) .560$ As stated above, the most important difference of this soil 561 compared to the others is its high electrical conductivity 562 derived from the presence of gypsum, which is related with 563 the ionic strength (Torrent et al., 2016), and also the synergic 564 presence of smectite clays, acting as an additional AgNP 565 trapping agent due to its surface properties and CEC features 566 (Solé et al., 1992). Several authors have pointed out that high 567 ionic strength favors nanoparticle adsorption when electro- 568 static repulsion is present (Dwivedi et al., 2015).

569

2.4. Recovery of AgNPs from soils using DIN 38414-S4 and 570 DTPA leaching procedures

To evaluate the mobility and bioavailability of different sized 572 and coated AgNPs retained in agricultural soils, two leaching 573 


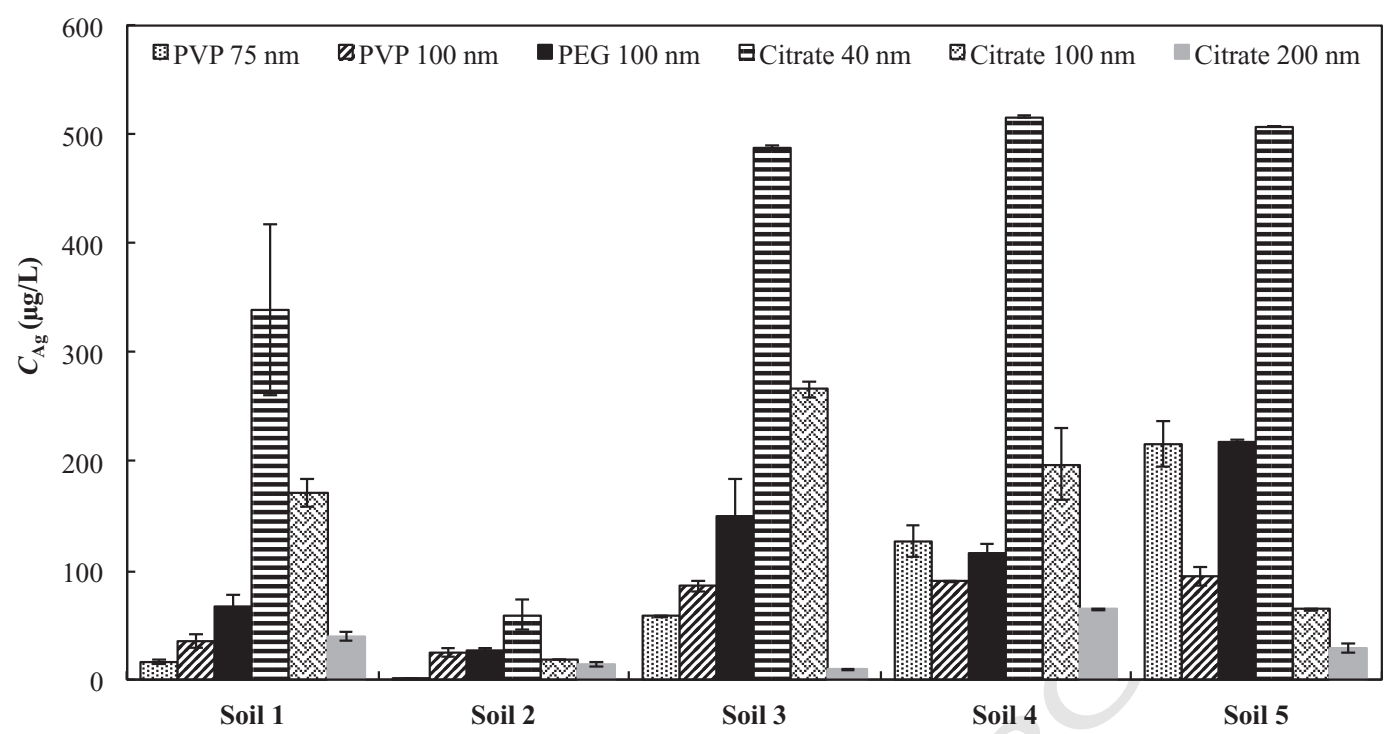

Fig. 2 - Silver supernatant concentration after $2 \mathrm{hr}$ adsorption in different soils $(0.5 \mathrm{~g}$ of soil and $20 \mathrm{~mL}$ of nanoparticle suspension with $1000 \mu \mathrm{g} / \mathrm{L}$ total silver concentration).

procedures were carried out after 3 weeks of being adsorbed. DIN 38414-S4 and DTPA leaching procedures were applied to Soil 3 to gain information on the potential risks associated with these pollutants. Results can be observed in Table 2. In this table, $\mu \mathrm{g} \mathrm{Aginitial}$ is the total silver amount in the initial suspension, which was put in contact with Soil 3 under rotary agitation $(35 \mathrm{r} / \mathrm{min}$ ) for $2 \mathrm{hr}$ and after this time, the suspension was centrifuged and the supernatant was separated, filtered and analyzed. The $\mu \mathrm{g} \mathrm{Ag}_{\text {supernatant }}$ is the total silver amount in the supernatant. After the separation from the supernatant, the soil was dried and kept at room temperature for 3 weeks. Finally, a DIN 38414-S4 or a DTPA leaching procedure was carried out and the silver concentration of this leachate was determined. From these values the total amount of silver in each case was determined ( $\mu$ g Agleached).
As can be seen, the DIN 38414-S4 procedure gave very low 589 recovery values for total silver, with ionic silver being the most 590 retained silver form together with $100 \mathrm{~nm}$ PVP-AgNPs (no 591 significant statistical differences by Student's t-test, $t_{\text {critical }}>t-592$ experimental). From the results of PVP and citrate coatings, it can be 593 concluded that small nanoparticles show a lower tendency to be 594 adsorbed and a higher trend toward desorption than larger 595 ones, especially $40 \mathrm{~nm}$ citrate-AgNPs with respect to 100 and 596 $200 \mathrm{~nm}$, because significant statistical differences were ob- 597 served (Student's t-test, $t_{\text {critical }}>t_{\text {experimental }}$. Significant statisti- 598 cal differences (one-way ANOVA test, $F_{\text {critical }}<F_{\text {experimental }}$ ) on 599 leaching recoveries for the differently coated AgNPs tested can 600 be also observed. In the leaching tests, fewer 1PVP-AgNPs 601 were leached, observing statistical differences (Student's t-test, 602 $t_{\text {critical }}>t_{\text {experimental }}$, in comparison to citrate-AgNPs and 603

\section{Table 2 - DIN 38414-S4 and DTPA leaching tests of Soil 3 after adsorption of AgNPs.}

\begin{tabular}{|c|c|c|c|c|c|}
\hline Leaching method & AgNPs & $\mu g$ Aginitial & $\mu g$ Agsupernatant & $\mu g$ Agleached & Recovery (\%) \\
\hline \multirow[t]{7}{*}{ DIN 38414-S4 } & PVP $75 \mathrm{~nm}$ & 19.7 & $0.6(0.1)$ & $0.16(0.02)$ & $0.8(0.1)$ \\
\hline & PVP $100 \mathrm{~nm}$ & 20.0 & $0.4(0.2)$ & $0.08(0.02)$ & $0.4(0.1)$ \\
\hline & PEG $100 \mathrm{~nm}$ & 18.6 & $1.1(0.5)$ & $0.21(0.02)$ & $1.2(0.2)$ \\
\hline & Citrate $40 \mathrm{~nm}$ & 20.3 & 9.8 & 0.5 & 4.6 \\
\hline & Citrate $100 \mathrm{~nm}$ & 20.2 & $5(2)$ & $0.165(0.003)$ & $1.1(0.1)$ \\
\hline & Citrate $200 \mathrm{~nm}$ & 20.3 & $1.6(0.5)$ & $0.14(0.03)$ & $0.8(0.2)$ \\
\hline & $\mathrm{Ag}^{+}$ & 20.6 & $0.160(0.008)$ & $0.09(0.01)$ & $0.4(0.1)$ \\
\hline \multirow[t]{7}{*}{ DTPA } & PVP $75 \mathrm{~nm}$ & 19.7 & $0.6(0.2)$ & $0.10(0.02)$ & $0.5(0.1)$ \\
\hline & PVP $100 \mathrm{~nm}$ & 20.0 & $0.6(0.2)$ & $0.8(0.1)$ & $3.9(0.5)$ \\
\hline & PEG $100 \mathrm{~nm}$ & 18.6 & $1.0(0.3)$ & $0.47(0.04)$ & $2.7(0.2)$ \\
\hline & Citrate $40 \mathrm{~nm}$ & 20.3 & 9.6 & 0.05 & 0.5 \\
\hline & Citrate $100 \mathrm{~nm}$ & 20.2 & $5(1)$ & $0.11(0.09)$ & $0.7(0.6)$ \\
\hline & Citrate $200 \mathrm{~nm}$ & 20.3 & $1.4(0.1)$ & $0.28(0.06)$ & $1.5(0.3)$ \\
\hline & $\mathrm{Ag}^{+}$ & 20.6 & $0.135(0.003)$ & $1.60(0.02)$ & $7.8(0.1)$ \\
\hline
\end{tabular}

DTPA: diethylenetriaminepentaacetic acid.

Values expressed as mean, $n=2$ (standard deviation), except for nanoparticles of $40 \mathrm{~nm}$ with citrate surface $(n=1)$. 
PEG-AgNPs. Therefore, PVP-AgNPs were more strongly retained than the other types of AgNPs tested in Soil 3. The DTPA leaching procedure gave higher recovery values than the DIN 38414-S4 extraction method, except for the smaller particles (40 and $75 \mathrm{~nm}$ ). Surprisingly, the tendencies were completely opposite to those observed using the DIN 38414-S4 procedure: smaller AgNPs gave lower recovery values than bigger ones and ionic silver was the most leached silver form, showing significant statistical differences with respect to tested AgNPs (one-way ANOVA test, $F_{\text {critical }}<F_{\text {experimental }}$ ). Similarly, for different coated AgNPs, opposite trends were observed. Significant statistical differences (Student's t-test, $t_{\text {critical }}<t_{\text {experimental }}$ ) were observed between citrate-AgNPs and PVP-AgNPs and PEGAgNPs, indicating that citrate-AgNPs were the least leached. The complexing capacity of DTPA for $\mathrm{Ag}^{+}$could partially explain
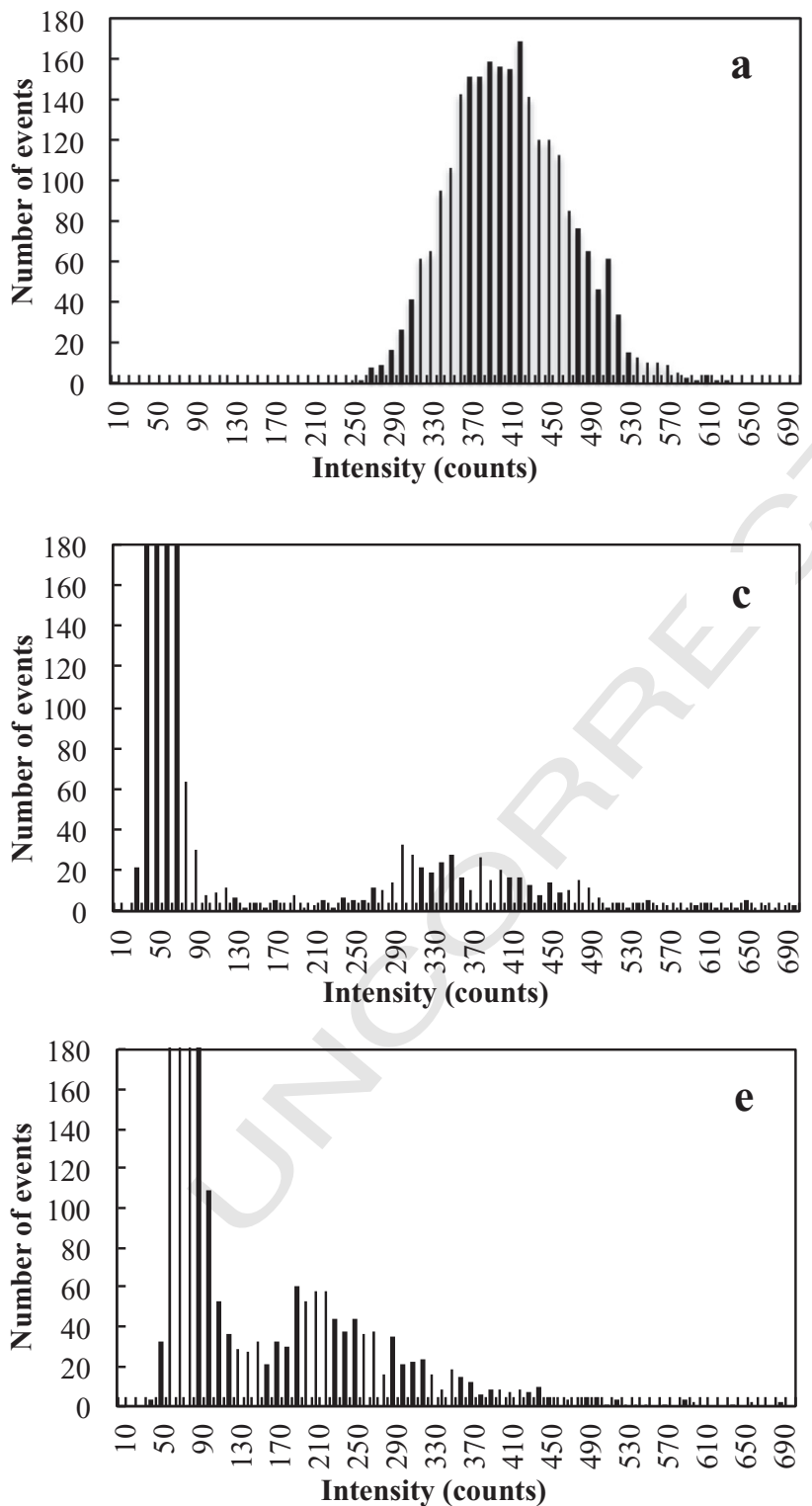

these results (Anderegg et al., 2005). As well, organic matter 619 content could have played a role in the stabilization of some of 620 the AgNPs (Klitzke et al., 2015; Liang et al., 2013). Some 621 differences in the leaching capability of these extraction 622 procedures were also observed for samples with different 623 characteristics (Marguí et al., 2004).

2.5. AgNP presence in leaching solutions by SP-ICP-MS

625

The interaction of nanoparticles with soils can lead to 626 transformations that alter their form and consequently their 627 behavior in the environment (Dwivedi et al., 2015). In order to 628 determine if silver nanoparticles maintain their nano-form 629 after the adsorption and desorption processes onto soils, 630 leachates from DIN 38414-S4 and DTPA tests were also 631
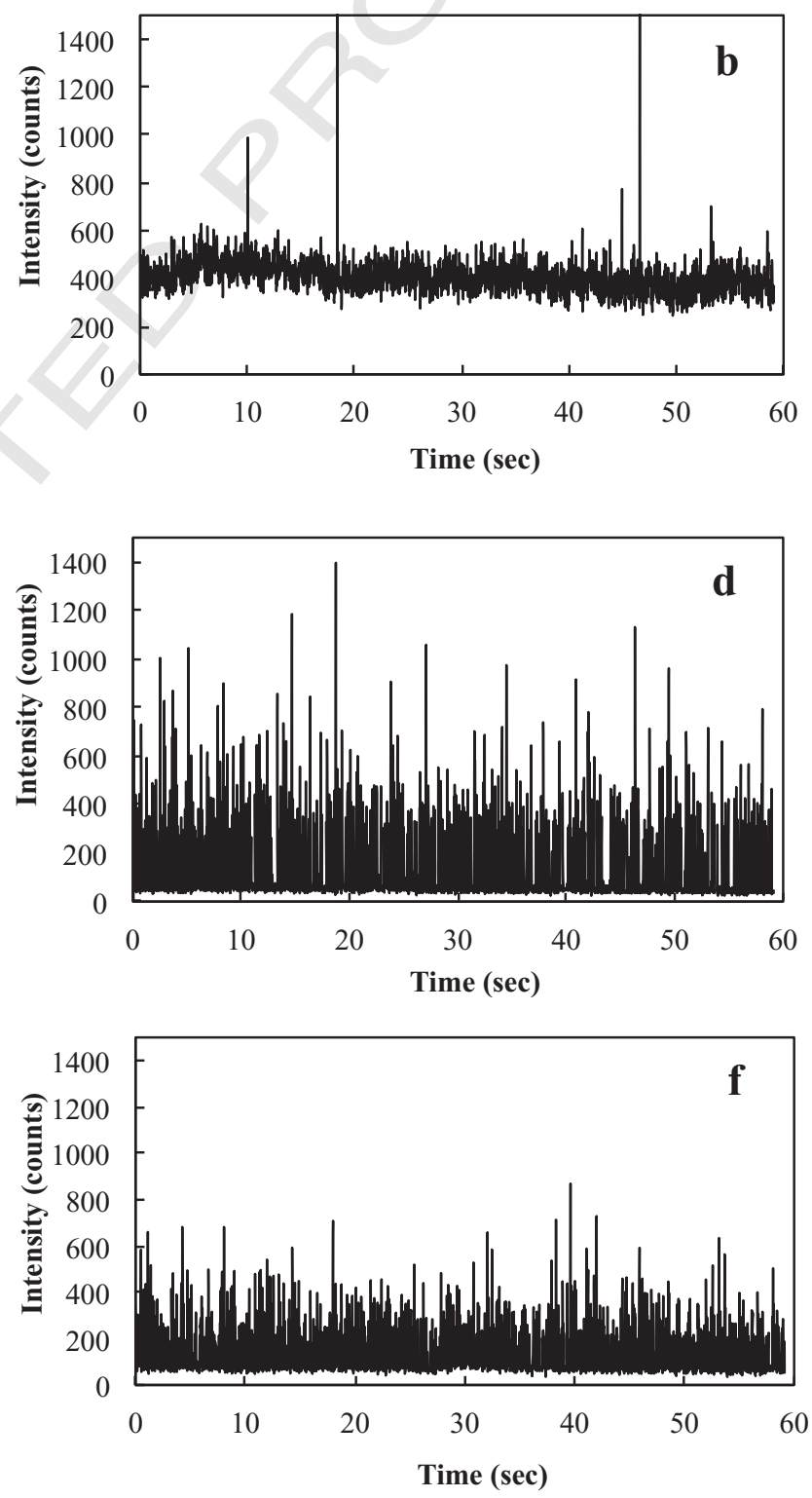

Fig. 3 - SP-ICP-MS histograms and time-resolved signal plots for polyethyleneglycol silver nanoparticles $100 \mathrm{~nm}$ (a, b), citrate silver nanoparticles $100 \mathrm{~nm}$ (c, d), polyvinylpyrrolidone silver nanoparticles $100 \mathrm{~nm}$ (e, f) from Soil 3 DIN 38414-S4 leachates. 
analyzed with SP-ICP-MS. As mentioned above, this analytical technique allows differentiating between nanoparticulate silver and dissolved silver.

As can be seen in the time-resolved signal plot obtained from SP-ICP-MS analysis of PEG-AgNPs DIN 38414-S4 leachates (Fig. 3b), the baseline counts were shifted to higher values (around 400 counts) and the signal was practically constant, indicating the presence of dissolved silver (Laborda et al., 2014). Although the presence of some peaks above the baseline was observed, they were not enough to confirm the presence of nanosilver. Therefore, during the adsorption or desorption processes, PEG-AgNPs were mainly dissolved. However, the presence of citrate-AgNPs in DIN 38414-S4 leachates was confirmed due to the large number of peaks present above the baseline, which is around 40 counts, indicating that there was also a small amount of dissolved silver (Fig. 3d). In addition, the histogram obtained from this measurement confirmed the presence of AgNPs, because two distributions could be observed (Fig. 3c). The distribution at low pulse intensity represents the dissolved silver, and that at higher pulse intensity values represents the nanoparticles. So, citrate-AgNPs maintained their nanoform after adsorption and desorption processes. Similarly, PVP-AgNPs of $100 \mathrm{~nm}$ size also maintained their form after the DIN 38414-S4 leaching procedure (Fig. 3e-f).

In the DIN 38414-S4 leachates of $200 \mathrm{~nm}$ citrate-AgNPs, the presence of nanosized particles was also confirmed, as shown in Fig. $4 c-d$. However, for citrate-AgNPs with dimension of $40 \mathrm{~nm}$, no nanoparticles were present (Fig. 4a-b). Therefore, it seems that smaller sized AgNPs are more prone to dissolution 661 in soil adsorption and desorption processes in comparison 662 with larger sized nanoparticles. These results agree with some 663 other results found in the literature (Dwivedi et al., 2015), 664 which mentioned a higher rate of dissolution for smaller 665 nanoparticles than for bigger ones due to the larger fraction of 666 surface atoms or the lower redox potentials of smaller AgNPs. 667

The leachates of $200 \mathrm{~nm}$ citrate-AgNPs for the five soils 668 studied were also analyzed in order to determine if there were 669 some differences in the AgNP forms caused by the physico- 670 chemical properties of the soils. In Fig. 5, it can be seen that 671 for Soils 1, 3 and 4, the silver nanoparticles maintain their 672 form after adsorption and desorption experiments. However, 673 for Soils 2 and 5, the presence of nanoparticles cannot be 674 confirmed (Fig. 5b and e). These two soils have a lower 675 amount of organic matter than the rest. Some studies have 676 related the presence of organic matter to the colloidal stability 677 of NPs due to electrostatic and steric interactions (Dwivedi et 678 al., 2015; Pachapur et al., 2016).

679

For the DTPA leaching procedure, the results obtained by 680 SP-ICP-MS analysis of leachates of different types of coated 681 AgNPs, different AgNPs sizes and different tested soils 682 indicated that silver was dissolved in all cases, except for 683 $75 \mathrm{~nm}$ PVP-AgNPs and $100 \mathrm{~nm}$ PEG-AgNPs leachates that 684 seem to contain some nanoparticles, due to the presence of 685 some peak pulses above the baseline (Appendix A Fig. S5). 686 Even in these two cases, the number of particles is very small, 687 as can be observed in the histograms (Appendix A Fig. S6). The 688 presence of mainly dissolved silver in all the DTPA leachates 689
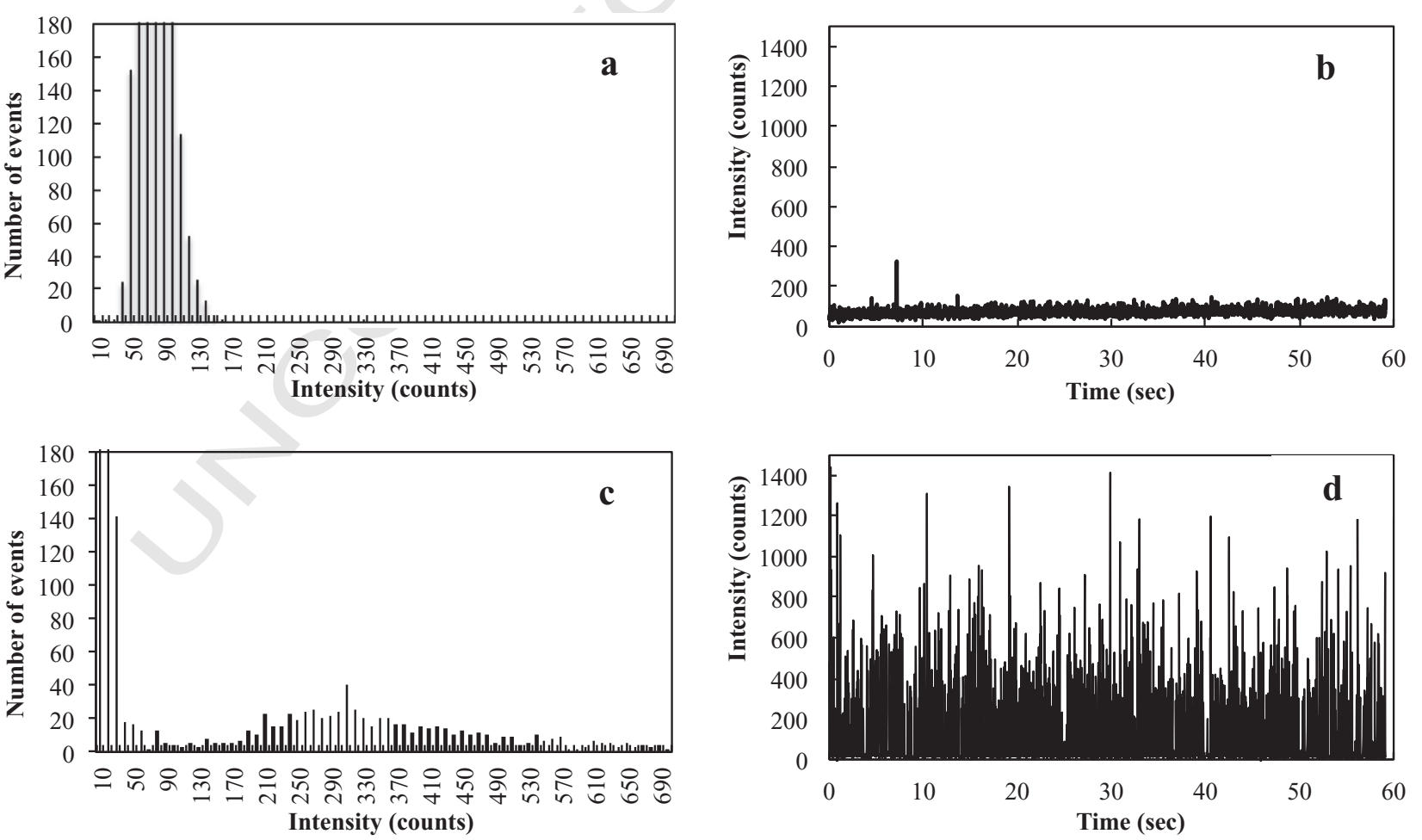

Fig. 4 - SP-ICP-MS histograms and time-resolved signal plots for citrate silver nanoparticles $40 \mathrm{~nm}(\mathrm{a}, \mathrm{b})$ and $200 \mathrm{~nm}$ citrate silver nanoparticles (c, d) from Soil 3 DIN 38414-S4 leachates. 

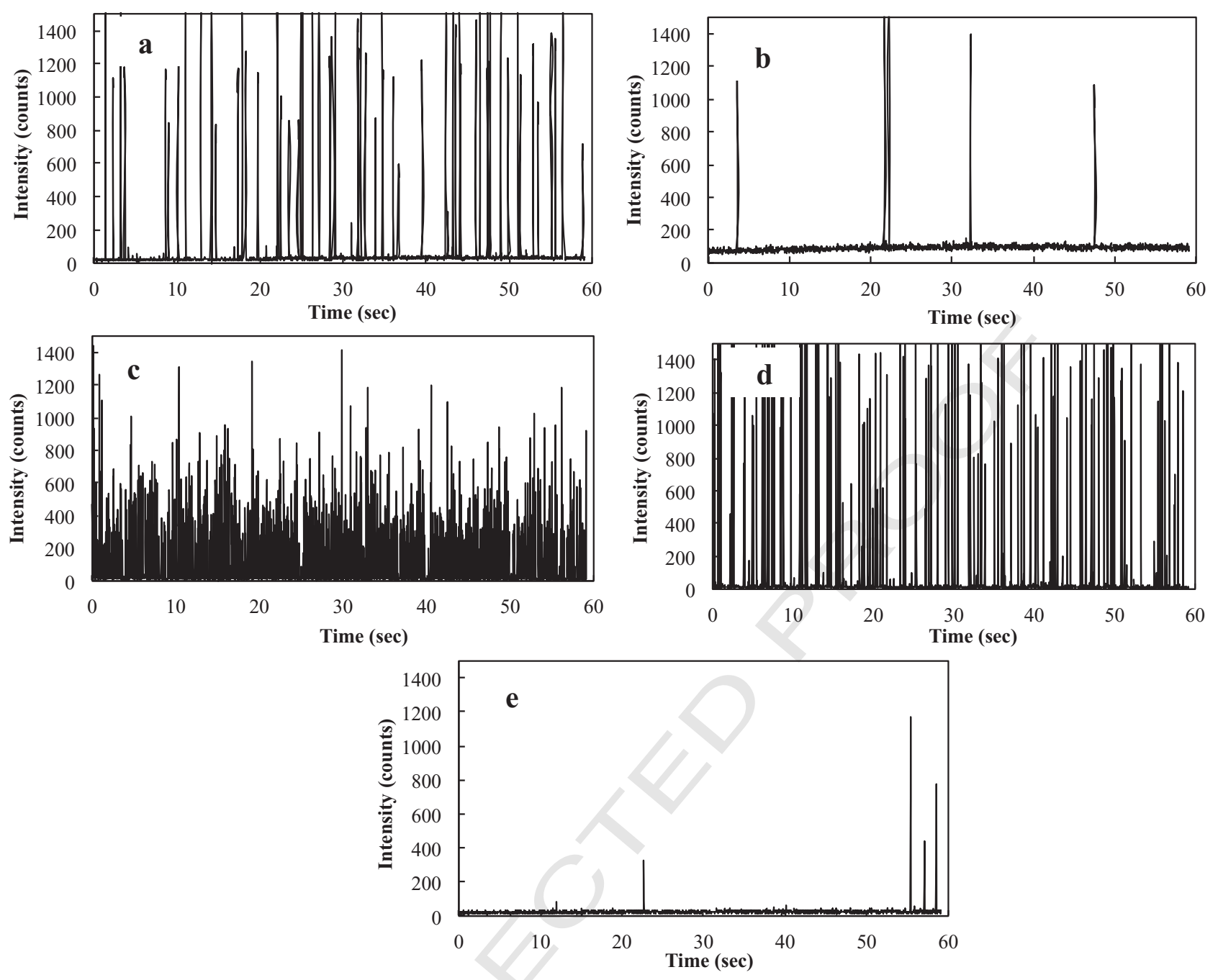

Fig. 5 - SP-ICP-MS time-resolved signal plots for $200 \mathrm{~nm}$ citrate silver nanoparticles obtained from DIN $38414-\mathrm{S} 4$ leaching experiments using Soil 1 (a), Soil 2 (b), Soil 3 (c), Soil 4 (d) and Soil 5 (e).

could be due to the complexation capacity of DTPA, which could leach silver ions $\left(\mathrm{Ag}^{+}\right)$strongly attached to soils, as was already observed (Table 2).

\section{Conclusions}

The interaction of AgNPs with soils and their transformations depend on several factors, including the physicochemical characteristics of the soil, the clay mineralogy, as well as the size and coating of the nanoparticles. The goal of the present work was to study the parameters that control the kinetic adsorption processes of AgNPs, including both those related to soil features and those affected by nanoparticle characteristics. The results showed that cation exchange capacity and electrical conductivity, which are related to soil clay mineralogy, are the main soil features affecting these processes. On the other hand, highly negatively charged citrate-coated AgNPs were retained less than almost neutral polyethyleneglycol-coated AgNPs and negatively charged polyvinylpyrrolidone-coated
AgNPs for most of the soils, organic matter content being one 708 of the factors that hampers their adsorption. Citrate-coated 709 AgNPs of different sizes showed slower retention of smaller 710 nanoparticles $(40 \mathrm{~nm})$ than bigger ones (100 and $200 \mathrm{~nm}$ ) in one 711 of the soils.

Soils were submitted to the leaching procedures 3 weeks 713 after the adsorption process. The results derived from the 714 analysis of the leachates confirmed the low mobility and 715 bioavailability of AgNPs. Only a small fraction of the nano- 716 particles $(<5 \%)$ was leached from soils. The smallest nano- 717 particles used in this work $(40 \mathrm{~nm})$ were more easily eluted 718 than larger ones (100 and $200 \mathrm{~nm}$ ) with DIN 38414-S4, being 719 transformed to soluble forms. It is also interesting to remark 720 that both the capping agent of the nanoparticle and soil 721 physicochemical characteristics seemed to have an effect on 722 the dissolution process of AgNPs. PEG-coated nanoparticles 723 were more easily dissolved than citrate- or PVP-coated ones, 724 and organic matter seemed to stabilize the nanoparticles, 725 avoiding their dissolution. Although this work clarifies some 726 aspects of AgNP adsorption and desorption behavior in soils, 727 


\section{R E F E R E N C E S} processes.

None. 1445-1495. 1896-1922. 326-343. more work is needed in order to completely understand these

\section{Declaration of conflicts of interest}

\section{Acknowledgments}

The Spanish Ministry of Economy and Competitiveness financed this work through the project CGL2013-48802-C3-2R (Program 2014) and L. Torrent gratefully acknowledges a FPI grant (Ref. BES-2014-070625). The authors are also thankful to Andreu Llort and Albert Salado for their contribution on the performance of this work and the University of Girona for financial support (MPCUdG2016/103).

\section{Appendix A. Supplementary data}

Supplementary data to this article can be found online at https://doi.org/10.1016/j.jes.2019.03.018.

Anderegg, G., Arnaud-Neu, F., Delgado, R., Felcman, J., Popov, K., 2005. Critical evaluation of stability constants of metal complexes of complexones for biomedical and environmental applications (IUPAC technical report). Pure Appl. Chem. 77,

Anjum, N.A., Gill, S.S., Duarte, A.C., Pereira, E., Ahmad, I., 2013. Silver nanoparticles in soil-plant systems. J. Nanopart. Res. 15,

Azimzada, A., Tufenkji, N., Wilkinson, K.J., 2017. Transformations of silver nanoparticles in wastewater effluents: links to $\mathrm{Ag}$ bioavailability. Environ. Sci. Nano 4, 1339-1349.

Barton, L.E., Therezien, M., Auffan, M., Bottero, J.-Y., Wiesner, M.R., 2014. Theory and methodology for determining nanoparticle affinity for heteroaggregation in environmental matrices using batch measurements. Environ. Eng. Sci. 31, 421-427.

Christian, P., Von der Kammer, F., Baalousha, M., Hofmann, Th., 2008. Nanoparticles: structure, properties, preparation and behaviour in environmental media. Ecotoxicology 17,

Cornelis, G., 2015. Fate descriptors for engineered nanoparticles: the good, the bad, and the ugly. Environ. Sci. Nano 2, 19-26.

Cornelis, G., Doolette, C., Thomas, Madeleine, McLaughlin, M.J., Kirby, J.K., Beak, D.G., Chittleborough, D., 2012. Retention and dissolution of engineered silver nanoparticles in natural soils Soil Sci. Soc. Am. J. 76, 891-902.

Cornelis, G., Pang, L., Doolette, C., Kirby, J.K., McLaughlin, M.J., 2013. Transport of silver nanoparticles in saturated columns of natural soils. Sci. Total Environ. 463-464, 120-130.

Coutris, C., Joner, E.J., Oughton, D.H., 2012. Aging and soil organic matter content affect the fate of silver nanoparticles in soil. Sci. Total Environ. 420, 327-333.

Dang, F., Jiang, Y., Li, M., Zhong, H., Peijnenburg, W.G.M., Shi, W., et al., 2018. Oral bioaccessibility of silver nanoparticles and ions in natural soils: importance of soil properties. Environ. Pollut. 243, 364-373.
Darlington, T.K., Neigh, A.M., Spencer, M.T., Nguyen, O.T., Oldenburg, S.J., 2009. Nanoparticle characteristics affecting environmental fate and transport through soil. Environ. Toxicol. Chem. 28, 1191-1199.

Dwivedi, A.D., Dubey, S.P., Sillanpää, M., Kwon, Y.-N., Lee, C., Varma, R.S., 2015. Fate of engineered nanoparticles: implications in the environment. Coord. Chem. Rev. 287, 64-78.

He, J., Wang, D., Zhou, D., 2019. Transport and retention of silver 790 nanoparticles in soil: effects of input concentration, particle 791 size and surface coating. Sci. Total Environ. 648, 102-108. 792

Hoppe, M., Mikutta, R., Utermann, J., Duijnisveld, W., 793 Guggenberger, G., 2014. Retention of sterically and 794 electrosterically stabilized silver nanoparticles in soils. Envi- 795 ron. Sci. Technol. 48, 12628-12635.

Hoppe, M., Mikutta, R., Utermann, J., Duijnisveld, W., Kaufhold, S., 797 Stange, C.F., et al., 2015. Remobilization of sterically stabilized 798 silver nanoparticles from farmland soils determined by $\quad 799$ column leaching. Eur. J. Soil Sci. 66, 898-909.

Ketterings, Q., Reid, S., Rao, R., 2007. Cation exchange capacity (CEC). Agron. Fact Sheet Ser. 22, 1-2.

Klitzke, S., Metreveli, G., Peters, A., Schaumann, G.E., Lang, F., 2015. The fate of silver nanoparticles in soil solution sorption of solutes and aggregation. Sci. Total Environ. 535, 54-60.

Koopmans, G.F., Hiemstra, T., Regelink, I.C., Molleman, B., $\quad 807$ Comans, R.N.J., 2015. Asymmetric flow field-flow fractionation 808 of manufactured silver nanoparticles spiked into soil solution. 809 J. Chromatogr. A 1392, 100-109.

Kosson, D.S., Van der Sloot, H.A., Eighmy, T.T., 1996. An approach 811 for estimation of contaminant release during utilization and 812 disposal of municipal waste combustion residues. J. Hazard. 813 Mater. 47, 43-75.

Laborda, F., Jiménez-Lamana, J., Bolea, E., Castillo, J.R., 2013. Critical considerations for the determination of nanoparticle 816 number concentrations, size and number size distributions by 817 single particle ICP-MS. J. Anal. At. Spectrom. 28, 1220-1232. 818

Laborda, F., Bolea, E., Jiménez-Lamana, J., 2014. Single particle 819 inductively coupled plasma mass spectrometry: a powerful $\quad 820$ tool for nanoanalysis. Anal. Chem. 86, 2270-2278. 821

legislation, German Standard, 1984. DIN 38414-S4: German Stan- 822 dards Methods for Examination of Water, Waste Water and 823 Sludge; Group S (Sludge and Sediments); Determination of 824 Leachability by Water (S4). Deutsches Institut für Normung E. 825 V. (DIN), Berlin. $\quad 826$

Li, M., Wang, P., Dang, F., Zhou, D.-M., 2017. The transformation 827 and fate of silver nanoparticles in paddy soil: effects of soil $\quad 828$ organic matter and redox conditions. Environ. Sci. Nano. 4, 829 919-928.

Liang, Y., Bradford, S.A., Simunek, J., Vereecken, H., Klumpp, E., 831 2013. Sensitivity of the transport and retention of stabilized 832 silver nanoparticles to physicochemical factors. Water Res. 47, 833 2572-2582.

Lin, S., Cheng, Y., Liu, J., Wiesner, M.R., 2012. Polymeric coatings 835 on silver nanoparticles hinder autoaggregation but enhance 836 attachment to uncoated surfaces. Langmuir 28, 4178-4186. 837

Majedi, S.M., Lee, H.K., 2016. Recent advances in the separation 838 and quantification of metallic nanoparticles and ions in the 839 environment. TrAC Trends Anal. Chem. 75, 183-196. 840

Marguí, E., Salvadó, V., Queralt, I., Hidalgo, M., 2004. Comparison 841 of three-stage sequential extraction and toxicity characteristic 842 leaching tests to evaluate metal mobility in mining wastes. 843 Anal. Chim. Acta 524, 151-159. 844

McGillicuddy, E., Murray, I., Kavanagh, S., Morrison, L., Fogarty, A., 845 Cormican, M., et al., 2017. Silver nanoparticles in the environ- 846 ment: sources, detection and ecotoxicology. Sci. Total Environ. 847 575, 231-246

Mitrano, D.M., Ranville, J.F., Bednar, A., Kazor, K., Hering, A.S., $\quad 849$ Higgins, C.P., 2014. Tracking dissolution of silver nanoparticles 850 at environmentally relevant concentrations in laboratory, $\quad 851$ 
natural, and processed waters using single particle ICP-MS (spICP-MS). Environ. Sci. Nano. 1, 248-259.

Montaño, M.D., Badiei, H.R., Bazargan, S., Ranville, J.F., 2014. Improvements in the detection and characterization of engineered nanoparticles using spICP-MS with microsecond dwell times. Environ. Sci. Nano. 1, 338-346.

Nanocomposix. Standard Capping Agents, 2018. . Available at: http://cdn.shopify.com/s/files/1/0257/8237/files/Standard_ Capping_Agents.pdf, Accessed date: 6 February 2018.

Navarro, D.A., Kirby, J.K., McLaughlin, M.J., Waddington, L., Kookana, R.S., 2014. Remobilisation of silver and silver sulphide nanoparticles in soils. Environ. Pollut. 193, 102-110.

Pachapur, V.L., Larios, A.D., Cledón, M., Brar, S.K., Verma, M., Surampalli, R.Y., 2016. Behavior and characterization of titanium dioxide and silver nanoparticles in soils. Sci. Total Environ. 563-564, 933-943

Peralta-Videa, J.R., Zhao, L., Lopez-Moreno, M.L., de la Rosa, G., Hong, J., Gardea-Torresdey, J.L., 2011. Nanomaterials and the environment: a review for the biennium 2008-2010. J. Hazard. Mater. 186, 1-15.

Plassard, F., Winiarski, T., Petit-Ramel, M., 2000. Retention and distribution of three heavy metals in a carbonated soil: comparison between batch and unsaturated column studies. J. Contam. Hydrol. 42, 99-111.

Praetorius, A., Tufenkji, N., Goss, K.-U., Scheringer, M., Von der Kammer, F., Elimelech, M., 2014. The road to nowhere: equilibrium partition coefficients for nanoparticles. Environ. Sci. Nano 1, 317-323.

Prathna, T.C., Chandrasekaran, N., Mukherjee, A., 2011. Studies on aggregation behaviour of silver nanoparticles in aqueous matrices: effect of surface functionalization and matrix composition. Colloids Surf. A: Physicochem. Eng. Asp. 390, 216-224.

Pulit-Prociak, J., Banach, M., 2016. Silver nanoparticles - a material of the future...? Open Chem. 14, 76-91.

Quevauviller, P., 1998. Operationally defined extraction procedures for soil and sediment analysis I. Standardization. TrAC Trends Anal. Chem. 17, 289-298.

Rauret, G., 1998. Extraction procedures for the determination of heavy metals in contaminated soil and sediment. Talanta 46 , 449-455.

Sajid, M., Ilyas, M., Basheer, C., Tariq, M., Daud, M., Baig, N., et al., 2015. Impact of nanoparticles on human and environment: review of toxicity factors, exposures, control strategies, and future prospects. Env. Sci. Pollut. Res. 22, 4122-4143.
Schultz, C., Powell, K., Crossley, A., Jurkschat, K., Kille, P., Morgan, 898 A.J., et al., 2015. Analytical approaches to support current 899 understanding of exposure, uptake and distributions of $\quad 900$ engineered nanoparticles by aquatic and terrestrial organisms. 901 Ecotoxicology 24, 239-261. 902

Sigfridsson, K., Lundqvist, A., Strimfors, M., 2013. Evaluation of 903 exposure properties after injection of nanosuspensions and 904 microsuspenions into the intraperitoneal space in rats. Drug 905 Dev. Ind. Pharm. 39, 1832-1839. 906

Simonet, B.M., Valcárcel, M., 2009. Monitoring nanoparticles in the 907 environment. Anal. Bioanal. Chem. 393, 17-21. 908

Solé, A., Plana, F., Gallart, F., Josa, R., Pardini, G., Aringhieri, R., 909 1992. How mudrock and soil physical properties influence 910 badland formation at Vallcebre (pre-pyrenees, NE Spain). $\quad 911$ Catena 19, 287-300. 912

Tech Note: Zeta/pH Curves and Isoelectric Point Data for Standard 913 Nanocomposix Silver Citrate and PVP Nanoparticle Disper- 914 sions. Available at:. https://cdn.shopify.com/s/files/1/0257/ 915 8237/files/Tech_Note_-_Zeta_and_pH_Curves_for__ 916 nanoComposix_Citrate_and_PVP_Capped_Silver_Nanoparti- 917 cles.pdf, Accessed date: 18 August 2017.

Torrent, L., Iglesias, M., Hidalgo, M., Marguí, E., 2016. Analytical 919 capabilities of total reflection X-ray fluorescence spectrometry 920 for silver nanoparticles determination in soil adsorption $\quad 921$ studies. Spectrochim. Acta Part B 126, 71-78. 922

Tourinho, P.S., Van Gestel, C.A.M., Lofts, S., Svendsen, C., Soares, 923 A.M.V.M., Loureiro, S., 2012. Metal-based nanoparticles in soil: 924 fate, behaviour and effects on soil invertebrates. Environ. $\quad 925$ Toxicol. Chem. 31, 1679-1692. 926

Treumann, S., Torkzaban, S., Bradford, S.A., Visalakshan, R.M., $\quad 927$ Page, D., 2014. An explanation for differences in the process of 928 colloid adsorption in batch and column studies. J. Contam. $\quad 929$ Hydrol. 164, 219-229.

Tuoriniemi, J., Cornelis, G., Hassellöv, M., 2012. Size discrimina- 931 tion and detection capabilities of single-particle ICPMS for 932 environmental analysis of silver nanoparticles. Anal. Chem. 933 84, 3965-3972.

Van Koetsem, F., Geremew, T.T., Wallaert, E., Verbeken, K., Van 935 der Meeren, P., Du Laing, G., 2015. Fate of engineered 936 nanomaterials in surface water: factors affecting interactions 937 of $\mathrm{Ag}$ and $\mathrm{CeO}_{2}$ nanoparticles with (re)suspended sediments. 938 Ecol. Eng. 80, 140-150. 939

Yang, Y., Long, C.-L., Yang, Z.-G., Li, H.-P., Wang, Q., 2014. Characterization and determination of silver nanoparticle $\quad 941$ using single particle-inductively coupled plasma-mass spec- 942 trometry. Chin. J. Anal. Chem. 42, 1553-1560. 943 